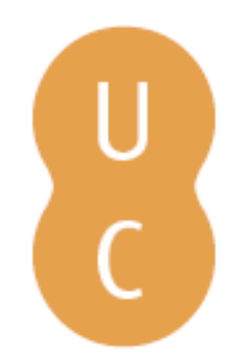

\title{
nommalina
}

\section{"Si grita un profeta hay que acercarse a ver" Algunas observaciones sobre el personaje del Pueblo de Zanzíbar en Les mame lles de Tiresias}

\author{
Autor(es): $\quad$ Sayar, Roberto Jesús \\ Publicado por: Imprensa da Universidade de Coimbra \\ URL \\ persistente: URI:http://hdl.handle.net/10316.2/42954 \\ DOI: $\quad$ DOI:https://doi.org/10.14195/978-989-26-1439-7_11 \\ Accessed : $\quad$ 26-Apr-2023 12:16:41
}

A navegação consulta e descarregamento dos títulos inseridos nas Bibliotecas Digitais UC Digitalis, UC Pombalina e UC Impactum, pressupõem a aceitação plena e sem reservas dos Termos e Condições de Uso destas Bibliotecas Digitais, disponíveis em https://digitalis.uc.pt/pt-pt/termos.

Conforme exposto nos referidos Termos e Condições de Uso, o descarregamento de títulos de acesso restrito requer uma licença válida de autorização devendo o utilizador aceder ao(s) documento(s) a partir de um endereço de IP da instituição detentora da supramencionada licença.

Ao utilizador é apenas permitido o descarregamento para uso pessoal, pelo que o emprego do(s) título(s) descarregado(s) para outro fim, designadamente comercial, carece de autorização do respetivo autor ou editor da obra.

Na medida em que todas as obras da UC Digitalis se encontram protegidas pelo Código do Direito de Autor e Direitos Conexos e demais legislação aplicável, toda a cópia, parcial ou total, deste documento, nos casos em que é legalmente admitida, deverá conter ou fazer-se acompanhar por este aviso.

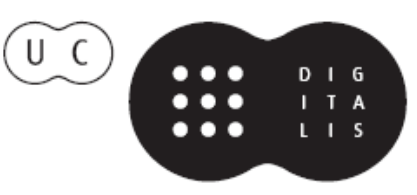




\section{Pervivencia del mundo clásico en la literatura:}

\section{tradición y relecturas}

\section{Aldo Rubén Pricco, Stella Maris Moro (coords.)}

IMPRENSA DA UNIVERSIDADE DE COIMBRA 


\title{
"Si GRITA UN PROFETA HAY QUE ACERCARSE A VER" Algunas observaciones sobre el personaje del Pueblo de ZANZíBAR EN LES MAMELLES DE TIRESIAS
}

("If a profet cries we must come and see". Some observations about the figure People of Zanzíbar in Les mamelles de Tiresias)

\author{
Roberto Jesús SAyar (sayar.roberto@gmail.com) \\ Universidad de Buenos Aires
}

Resumen - Invocando el concepto de "unión del arte con la vida" y como un punto de partida de la "aniquilación de la institución arte" (ambas premisas fundamentales para la concepción del teatro de las vanguardias históricas) se intentará en este trabajo abordar el análisis de la obra Les Mamelles de Tirésias (1917) de Guillaume Apollinaire haciendo foco en la recuperación de estructuras del teatro pre-moderno, que los esquemas teatrales dominantes hasta ese momento habían desdeñado como no pertenecientes a la esfera de lo dramático. Dirigiremos la mirada particularmente a los procedimientos que esta obra toma del teatro de la Antigüedad Clásica, corporizados casi exclusivamente por el personaje-multitud del Pueblo de Zanzibar. Dentro de estos, subrayaremos en especial el peso que toma en la construcción del personaje y sus acciones en escena la antigua figura del mimetés y las prácticas con este asociadas. Además destacaremos por sobretodo -y mucho más profundamente- los momentos corales que protagoniza, que consideramos parte nodal de esta pieza, debido a que no solo son los que hacen avanzar la obra sino que son los que ayudan a su correcta comprensión. Esperamos con este trabajo demostrar todo el peso específico que este personaje tuvo en la construcción del texto, de tal manera que todo él sea, al fin y al cabo, un transitar por la cornisa de las estructuras del teatro y un interesante salto al abismo del futuro, sin (y, diríamos, a causa de no) dejar de contemplar el más remoto pasado.

Palabras Clave: Surrealismo, procedimientos teatrales, pre-modernidad, Apollinaire.

Aвstract - Taking the concept of "fusion of art and life", and as a starting point to the "annihilation of the institution of art" (two fundamental premises in the understanding of theatre by the historical avant-garde movements), this paper endeavors to analyze Guillaume Apollinaire's Les Mamelles de Tirésias (1917), focusing on the reappearance of pre-modern theatre structures, which the theatre standards that had dominated up to that moment disdained for not belonging to the sphere of the dramatic. In particular, we shall cast our attention towards the procedures that this play incorporates from the theater of the Classical Antiquity, almost exclusively embodied by the character-crowd of the People of Zanzibar. Within these, we shall underline the special relevance that the ancient figure of the mimetés and his associated practices have in the construction of the character and its performance on stage. Above all, we shall highlight-much more deeply- the choral moments where he appears, which we consider as a nodal part of this 
play, not only because they make it move forwards but because they also contribute to the play's correct understanding. This paper aims at proving the specific relevance that this character had on the construction of the text, so it becomes a way of walking on the limit of theatre structures and an interesting leap towards the abyss of the future, without ceasing to contemplate the most distant past.

Keywords: Surrealism, theatrical procedures, pre-modernity, Apollinaire.

En el año 1917 una obra sumamente extraña tomó por sorpresa a los asistentes al teatro Reneé Maubel de París. La producción en cuestión se titulaba Les Mamelles de Tirésias y su autor era un tal Guillaume Apollinaire. Compuesta en 1903, con tan solo veintitrés años, buscaría con ella, en sus propias palabras, "intentar [...] volver a la naturaleza misma, pero sin imitarla a la manera de los fotógrafos” (2009: 100). En esta pieza la protagonista del drama, Teresa, cansada de las exigencias que la sociedad instaura sobre su sexo decide cambiar de género (y con él, de nombre) para obtener así poder entre los hombres mientras que su marido, obligado por ella a raíz de esta acción a emularla y ocupar así su lugar, procrea por sí solo una vasta cantidad de hijos en sólo una noche. Finalmente la esposa retorna al hogar y todo termina con baile y canto. A grandes rasgos y demasiado superficialmente, ese es el argumento de la pieza que nos ocupará en este trabajo. Esto puede parecer, grosso modo, algo medianamente coherente que se sirve de la fantasía para expresar algo particularmente difícil, pero la transmisión del "discurso directivo" (AA.VV.: 11) no es el sólo fin de la pieza. Pues, de otro modo, cómo podrían algunos estudiosos afirmar que "Apollinare est un charmeur. Il creé [...] un spectacle déconcertant, un spectacle où la raison se perd, qui laisse tout au plus entrevoir sa raison d'être et son sujet" (Lusseryan 1961: 129) si la pieza no fuera precisamente más de lo que aparenta.

No será nuestro propósito analizar la totalidad de la misma, pero creemos necesario contextualizarla para poder encarar el análisis habiendo sentado algunas bases teóricas en las que sustentarlo. Si leemos un poco más detalladamente la obra notaremos varias aristas que la destacan del resto de la producción teatral circulante por aquellos años. Claro exponente de las llamadas posteriormente "vanguardias artísticas" y puntualmente elemento de bautismo de una de las corrientes que la conformaron ${ }^{1}$, la pieza nos regala un abanico de procedimientos específicos de esta nueva poética² ${ }^{2}$ mediante los cuales se busca

${ }^{1}$ Cuya primera aplicación descriptiva del arte contemporáneo no es la que aparece en esta obra sino más bien en el artículo "Parade y el espíritu nuevo" firmado por el mismo Apollinaire y publicado en el programa de mano de su estreno.

${ }^{2}$ Entendemos poética en el sentido que le otorga Dubatti (2008a: 76-77) y de tal modo enmarcamos a las "vanguardias artísticas", siguiéndolo, como una archipoética (para la definición de este concepto, véase Dubatti 2008a: 80) divergente de las que la precedieron, en particular de la simbolista, de la que representa una profundización (cf. Dubatti 2009: 170). 
al mismo tiempo polemizar y criticar al teatro anterior, buscar forjar un vínculo entre el arte y la vida más profundo que el planteado por el simbolismo y, derivado de todo esto, la aniquilación de la institución misma del arte. Para llevar a cabo estos fines, que se plantean como fundamentos, el teatro de vanguardia trabajará sobre un tridente de procedimientos complementarios entre sí: la violencia destructiva sobre las estructuras precedentes por vía de la parodia; un abanico de "procedimientos originales" (AA.VV.: 8) para plasmar en ellos los conflictos y las posibles resoluciones de las tensiones entre el arte y la vida y, por último, la recuperación de estructuras del llamado "teatro pre-moderno»3. Será este último punto el que nos conduzca hasta nuestro interés particular dentro de esta más que particular pieza: El personaje del Pueblo de Zanzíbar y su posible retrotracción a las estructuras corales y miméticas del teatro griego clásico, y junto a él las apariciones corales propiamente dichas que esta obra ostenta.

Si intentásemos colocar a tal concepto de personaje en una concepción "realista-objetivista" del teatro como la que hasta ese momento disfrutaba de la aceptación general del público veremos tal tarea cómo imposible. Por empezar, el Pueblo es un personaje colectivo: una única persona que representa a toda una multiplicidad. Más allá de que la acción se sitúe en $Z_{\text {anzíbar }}^{5}$, si consideramos que la ilusión de contigüidad constitutiva de la poética realista del drama moderno (Dubatti 2009: 42) debería de abarcar a todo el mundo y no solo al burgués occidental, el mero desplazamiento regional no justificaría tal corrimiento de dicha ilusión de manera que se impida el simple acto de constatar en la escena el hecho empírico de que una persona no puede ser más de una ${ }^{6}$. Y si bien con este movimiento se logra salir del centro "civilizador" europeo, no podríamos afirmar sin más que a causa de estar en África la realidad se ve trastocada en sus mismos cimientos. Pero Apollinaire así lo quiere, por lo que intentaremos dilucidar por qué lo ha buscado de este modo y si es que con esto se acerca o no a una verdadera imitación de la naturaleza como la que explicita que busca en su descripción programática del prólogo.

"Todos los teatros son arcaicos" nos dice Eugenio Barba (2002: 18) por lo cual comenzamos a entender alguna de las causas acerca del por qué de las particularidades de esta obra. El mismo Apollinaire dirá que esta es su manera de "interpretar la naturaleza" (2009: 100) y de esa manera "volverse inhumano[s]" (1995: 62). Si entendemos entonces lo "inhumano" como lo "natural" y la manera de retornar a los orígenes, y más aún si tenemos en consideración

${ }^{3}$ La periodización a la que pertenece este concepto aparece en Dubatti 2009: 23-28.

${ }^{4}$ En adelante: "Pueblo" o $P Z$.

${ }^{5}$ Isla de Tanzania en el Océano Índico y ciudad capital de la misma y del Territorio Autónomo homónimo (Fuente: (2005), Gran Enciclopedia Universal. Vol. 40. Buenos Aires: Espasa Calpe).

${ }^{6}$ Porque violaría el principio de no contradicción. Cf. Metaph. 1005 b18 y ss. 
las palabras del Filósofo cuando afirma que "el imitar es connatural al hombre desde la infancia» ${ }^{7}$ podremos ver con mayor claridad por qué nuestro autor buscó para su personaje un procedimiento tan característico del teatro clásico como es el del coro dada su mayor antigüedad y su remarcado carácter sagrado y los vínculos que esta esfera mantiene con la naturaleza toda. Recordemos además que dentro de la economía del certamen dionisíaco, el coro es lo que primariamente retrotrae a todo el aparato teatral hacia la religión y lo sagrado más que los actores que encarnan a los personajes. En este sentido, el Pueblo es todo él un coro y por ende todo él un vínculo con estas esferas metafísicas. El baile coral alrededor del altar de Dioniso vehicula las energías del universo hacia los coreutas y desde ellos se producirá luego la kátharsis que tantas veces se le ha adjudicado a la tragedia y antes de ella a los poetas ditirámbicos (cf. Macgowan y Melnitz 1966: 24; Finley 1964: 102). La función del Pueblo, entonces, será la de ser un superconjunto en donde se intersecten todos los personajes menores de la obra (cf. La Charite 1968: 5); es decir, todos a excepción de él, de manera que a través suyo la obra sea un canal por el cual la naturaleza halle su camino hacia las personas participantes del acontecimiento teatral. En favor a esta teoría nótese que el Pueblo es el primero de los personajes que se halla en escena (pero que no entra a ella como el coro clásico) y el último en salir de la obra, entre danzas y música, lo que lo habilitaría a colocarse a si mismo como un factor interpretativo insoslayable de la arquitectura de la pieza.

No contento con esto, Apollinaire coloca a su Pueblo en un papel similar, si no calcado, al del antiguo mimo clásico. Recordamos, sucintamente, que en aquel se representaban sucesos de la vida real pero con una gran cuota de improvisación en base a temas o motivos recurrentes -ausentes de la comediografía o el drama satírico ${ }^{8}$-. Si retornamos a las palabras de Barba (2002: 18) leeremos en él que "lo esencial solo puede ser mudo" y, si recordamos además que en el mimo la palabra tenía un valor relativo (Melero 1981/1983: 36), gracias a su virtual esquematicidad, podemos entonces añadir una trama más a la tela que tejemos en torno a nuestro personaje. El silencio glotal al que se ve condenado desde el principio mismo de la representación, para indicar que mediante él podrá accederse a otro nivel de realidad más cercano a lo metafísico, si se nos permite

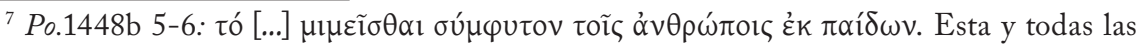
traducciones siguientes de textos griegos nos pertenecen.

8 Con el término "ausentes" nos referimos a que generalmente no eran tratados por la comedia o el drama de sátiros ateniense debido a su grado de selectividad, que si bien no excesivamente alto, dejaba fuera de escena temas improcedentes, inoportunos, inadecuados o inauditos, toda una gama de posibilidades listas a ser cubiertas por el mimo (Melero 1981-1983: 22; cf. Giantsou-Watrinet 2010). No quisimos expresar con ello que la comedia careciera de temas recurrentes, afirmación disparatada por demás, dado el extenso espectro de motivos que la comedia ha creado y explotado. Cavallero 1996 posee un extensísimo y bien documentado estudio al respecto. 
el término, se ve equilibrado gracias a los procedimientos expresivos de los que hace gala y que oscilan entre los sonidos heteróclitos de sus instrumentos que se desarrollarán en sí mismos como elementos sígnicos, en el sentido saussureano del término, y los carteles que despliega en la escena cuarta. Vayamos por orden.

Los sones que aparecen a través de los objetos que manipula el personaje nos pueden remitir a muchas situaciones, habida cuenta de que en nuestra obra, como primera cuestión, "el diálogo se subordina a la acción" (La Charite 1968: 6), además es necesario recordar que según el autor "la música ocupa un lugar [...] importante [en la vida de los Antiguos]" (Apollinaire 1999: 138) y sobre todo que, para él, "la música <es> literatura" (Apollinaire 1995: 64). La suma de estos tres factores logran que las intervenciones del Pueblo, si son rastreadas a lo largo de la obra siguiendo la indicación del propio autor, formen todas ellas un código de lectura propio con correlatividades más o menos fijas entre el sonido que se efectúa y la acción que es representada por él. Para dar unos ejemplos representativos, podemos citar el tan característico sonido de "vajilla rota" que se escucha por primera vez (para repetirse en dos ocasiones más) cuando se oye fuera de escena la voz del marido o el ruido del trueno que, en las situaciones que aparece -también tres-, preludia una situación de violencia contra lo "naturalmente establecido". Igualmente, y a pesar de estos ejemplos, el sonido que, creemos, tiene más significación en todo este abanico auditivo, en relación a la “mimeticidad" del PZ, es el del revólver y los tiros.

En efecto, estos no solo nos indican la inminencia de una muerte y el rechazo del autor por la guerra. Los tiros de revolver hacen que acontezcan "muertes" en escena y, conjeturamos, es esa la razón por la cual no son los duelistas Presto y Lacouf los que efectivamente se disparan sino que "delegan” el hecho en el Pueblo para no manchar la escena con actos de impureza dignos de la ob-scenidad clásica. Recordamos, para afirmar esto, que el Pueblo se halla siempre detrás en el escenario y que en esta obra acontecen escenas paralelas con relativa frecuencia. En estas ocasiones, la aparición del Pueblo representaría cabalmente la intervención coral en la tragedia ya que no solo canaliza a través de él los sonidos que conllevan acontecimientos nodales ${ }^{9}$ sino que, además, explicita las condiciones de lectura de esos acontecimientos, cual un corifeo (función que, en el ámbito clásico, más adelante será tomada por el más conocido personaje del mensajero). Siguiendo con los acuerdos de silencio plasmados al principio, no las dirá en voz alta, sino mediante un par de pancartas, dándole un lugar predominante al lenguaje sin que este aparezca en su corporeidad sonora. El contenido de ambas jugará además con lo que se definen como "procedimientos de la liminalidad", es decir, -entre otros- la discusión sobre el lugar de los acontecimientos. De tal modo, mediante esta

\footnotetext{
${ }^{9}$ Entre numerosos ejemplos destacamos los versos 1119-1120 del Agamenón esquíleo.
} 
instalación la interpretación locativa parece no cerrarse a propósito; razón primaria para que los duelistas no mueran y vuelvan a alzarse apenas nuestro personaje finalice la instalación de las pancartas (el "estásimo" ${ }^{10}$ ) para volver a caer ante los ojos no solo del público sino también de Teresa, que no parece atender a tales sucesos. Esta intervención aclara notablemente el asunto gracias a los mismos términos que utiliza. Ambos duelistas deben morir porque ambos tienen razón, y de ese modo ambos habrían ganado la apuesta. Presto afirma que se hallan en Zanzíbar, y es cierto: Presto y Lacouf así como el resto de los personajes están en una escena (scène) ubicada en la ciudad de Zanzíbar. Pero al mismo tiempo, Lacouf sostiene que se hallan en París, y también es cierto: Yéta Daesslé (Lacouf) y Edmond Valée (Presto) están en un teatro de la ciudad de París. Más allá de esta explicación un tanto digresiva, apelamos a ella para dar a entender el rol de pueblo como coro teniendo en cuenta que "es preciso considerar al coro <como uno > de los actores, <esto $>$ es, considerar $<$ lo $>$ una parte del todo y coparticipar <en la acción> (Po. 1456a 25-2711) más aún si recordamos, como bosquejamos más arriba, el hecho de que la tragedia como hecho artístico-religioso se deriva de los ditirambos, cantos religiosos cantados por un coro con entonadores (cf. Lesky 2001: 86). Establecido entonces que el coro es el que tradicionalmente hace avanzar la trama trágica, debido a que es otro actor dentro de los dramatis personae, podremos entonces comprender un poco más profundamente el sentido sígnico de los sonidos y ruidos que este realiza, e incluso, catafóricamente, de su segunda intervención "coral" de manera impresa: la pancarta con el estribillo.

Esta reza de la siguiente manera:

EH! FUMEZ LA PIPE BERGÈRE

MOI JE VOUS JOUERAI DU PIPEAU

ET CEPENDANT LA BOULANGĖRE

TOUT LES 7 ANS CHANGEAIT DE PEAU

TOUT LES 7 ANS ELLE EXAGÈRE

¡EH! FUME LA PIPA PASTORA

YO TOCARÉ LA FLAUTA PARA USTED

Y SIN EMBARGO LA VENDEDORA

CADA SIETE AÑOS CAMBIA LA PIEL

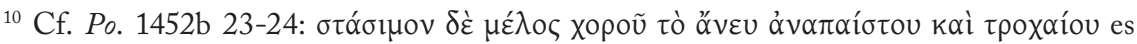
decir "[...] estásimo es la canción del coro <con> el faltante de anapestos y troqueos". Los primeros suceden primordialmente en la párodos y los segundos en el éxodos. Consideramos esta acción del $P Z$ como un estásimo debido a que en ella se concentra toda la primer actividad coral de nuestro personaje.

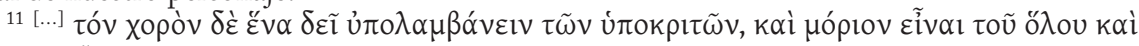
$\sigma u v \alpha \gamma \omega v i ́ \zeta \varepsilon \sigma \theta \alpha 1$. 
"Si grita un profeta hay que acercarse a ver". Algunas observaciones sobre el personaje del Pueblo de Zanzíbar en Les mamelles de Tiresias

\section{CADA SIETE AÑOS QUÉ CAMBIADORA ${ }^{12}$.}

En este pasaje, como primera medida, no debe pasarnos desapercibido que lo que hace el Pueblo en esencia es trasladar los parlamentos inmediatamente anteriores del gendarme y del marido que, colocados en el contexto de la declaración de amor del primero hacia el segundo, nos traslada hacia un ámbito por demás obsceno ${ }^{13}$, diríamos en esta ocasión más típico del mimo que de la tragedia, no ya de la comedia por las razones que anteriormente hemos expuesto. Esto se hace todavía más notorio si nos trasladamos al final del acto, en donde esta canción es bailada por todos en pareja a excepción de nuestro $P Z$ que baila solo tocando el acordeón. Creemos que con esta intervención lo que se busca es resaltar los aspectos festivos de este convivio ${ }^{14}$ teatral por sobre los funestos de la guerra que circunda a la Ciudad Luz, representados por el sonido del instrumento del Pueblo ${ }^{15}$. Es sobretodo teniendo en cuenta este concepto y su profunda aplicación que notamos la "coralidad" del $P Z$ pues al llevar a todos los participantes de la pieza, incluso a él mismo, a un festejo cuasi-dionisíaco, profundiza la reunión entre los presentes y los vínculos que se establecen entre ellos buscando, quizás, terminar de disolver la separación entre actores y espectadores, que -creemos- alcanzará su punto álgido con la participación de la dama del público (Acto II, escena VIII).

Como corolario a este desempeño coral del final del primer acto, podremos ver uno similar al final de la pieza en donde la burla lasciva parece dejar paso a una más relajada, y no por eso menos movida, animación jocosa en donde nuestro personaje abandona el acordeón y los reemplaza por unos cascabeles, que en sus dos apariciones anteriores parecen significar escenas tan alusivas sexualmente como las que parecía haber abandonado. Lo destacable aquí, no obstante, no es el tenor de la jocosidad que se pretende transmitir -"contagiar"16 se acercaría mejor a lo que parece buscar- sino más bien la posición destacada de estos interludios que, más allá de remitir sonoramente a la comedia néa griega y a toda la latina (cf. Lesky 2001: 373), nos conducen a un destacado motivo cómico que es el de finalizar la pieza con una celebración y un leve

${ }^{12}$ Esta traducción y las siguientes correspondientes a la obra -salvo indicación en contrariosiguen la versión establecida por Fiszman y detallada en sección 'Bibliografía'.

${ }^{13}$ Dado que, como nos aclara el traductor de nuestra edición en nota ad loc: "Tanto pipe como pipeau en el argot francés significan pene. Fumer une pipe es la felación, y bergère puede usarse tanto para esposa como para mujer fácil" (Apollinaire 2009: 140).

${ }^{14}$ Entendemos "convivio" como lo hace Dubatti 2008: 28.

${ }^{15}$ Realmente creemos que, siguiendo las correlaciones sígnicas de los sonidos, el acordeón representa a la justicia más que a la guerra propiamente dicha, pero lo referimos de esta manera dado que este parece representar la superposición coercitiva/violenta de la justicia y cómo tal podría equiparase a una situación bélica.

${ }^{16}$ En el sentido dado a este término por Artaud 2001 [1978]: passim. 
discurso directivo (también presente en su clásica antecesora, por boca ya de los personajes [Ach. 1231] ya del propio coro [Thesm. 1226 y ss.]) para que la pieza surta su efecto purificador sobre los presentes ${ }^{17}$. Pero entonces nos quedaría pendiente una crucial pregunta: ¿Cómo puede haber planificado su drama el autor si claramente en él predominan procedimientos pertenecientes a ámbitos aparentemente tan disímiles como el mimo, asentado sobre la improvisación, y la tragedia, de profundo planeamiento, como lo atestigua su literalidad?

Aquí haremos una salvedad citando al mismo Apollinaire, cuando en su prólogo nos dice claramente que:

\section{Selon le cas, le tragique l'emportera sur le comique ou inversement.}

Según el caso, lo trágico se impondrá a lo cómico o viceversa.

Esta frase en su contexto hace referencia a la necesidad de la creación de obras teatrales en donde ambos ámbitos necesariamente pasen a coexistir gracias a dos elementos constitutivos del futuro hipotético planteado en el prólogo: la energía de las jóvenes letras contemporáneas y el hecho de que el teatro "no es la vida que representa" (2009: 104). Recordemos además que nuestro autor no encajonó a su texto en ninguno de los géne constitutivos del teatro clásico, pues -con gran tinolo llamó drame (drama), es decir "acción", "para establecer lo que la diferencia de esas comedias de segundo orden a las cuales se llama simplemente 'obras"' (2009: 99). Tomando al pie de la letra su afirmación de que escribió su pieza "para los franceses, como Aristófanes componía sus comedias para los atenienses" (2009: 102) podríamos afirmar que estaría brindando una fructífera hipótesis de lectura, pero dado que ha rechazado la categorización esquemática típica del teatro anterior, deberemos ver en ella sus trazas y con esas bases reconstruir lo que podamos siguiendo lo que veamos (o, en nuestro caso particular, lo que leemos).

$\mathrm{Si}$, finalmente, este texto no responde de ningún modo de manera completa a una dramaturgia "de actor" ${ }^{18}$, como debería de hacerlo habida cuenta el peso específico que posee el personaje que acapara esos procedimientos tan característicos del mimo - que esperamos haber demostrado- creemos que es de esta manera como el autor busca, navegando los límites pero sin salirse completamente de las estructuras que le fueron heredadas, "protestar contra ese teatro engañoso que representa lo más claro del arte teatral de hoy" sin dejar por eso de "rendirles el homenaje" a quienes hicieron avanzar la humanidad mostrándoles mundos nuevos que "multiplican su visión"

Esperamos, con este análisis de la estructura bifronte de nuestro, a estas alturas querido, Pueblo de Zanzibar; con una cara mirando hacia el mimo y la

\footnotetext{
${ }^{17}$ Cf. Janko 1987.

${ }^{18}$ Cf. Dubatti 2008b: 11.
} 
"Si grita un profeta hay que acercarse a ver". Algunas observaciones sobre el personaje del Pueblo de Zanzíbar en Les mamelles de Tiresias comedia y la otra hacia el ditirambo y la tragedia, siempre avanzando -pancarta e instrumentos en mano- a descubrir los vínculos que lo unen a él y a sus conciudadanos tanto con el pasado más remoto como con el futuro más inesperado haber abierto al menos una puerta "aux découvertes les plus surprenantes". 


\section{Bibliografía}

\section{Fuentes}

Apollinaire, G., Les Mamelles de Tiresias [en línea] Disponible en internet en: http://www.hs-augsburg.de/ harsch/gallica/Chronologie/20siecle/ Apollinaire/apo ma02 .html

Apollinaire, G. (2009), El encantador putrefacto y Las tetas de Tiresias. Trad. Fiszman, M. Buenos Aires: Losada.

Janko, R. (1987), Aristotle. Poetics I. With the Tractatus Coislinianus. A Hypothetical Reconstruction of Poetics II. Indianapolis \& Cambridge: Hackett.

Kassel, R. (ed.) (1965), Aristotelis de arte poetica liber. Oxford: Clarendon Press. Ross, W. D. (ed.) (1970), Aristotle's Metaphysics. I-II. Oxford: Clarendon Press.

\section{Bibliografía SECUNDARIA}

AA. VV. (2012), Historia del teatro universal. Teóricos VIII-IX (miércoles 9 y 16 de mayo de 2012). Material para uso exclusivo de los alumnos de la cátedra Historia del Teatro Universal de la carrera de Artes de la FFyL de la UBA.

Apollinaire, G. (1999), "Parade y el espíritu nuevo", in Sánchez, J. A., La escena moderna. Manifiestos y textos sobre teatro de la época de las vanguardias. Madrid, Akal: 138-139.

Apollinaire, G. (1995), "Los pintores cubistas", in Cirlot, L., Primeras vanguardias artísticas. Textos y documentos. Barcelona, Labor: 59-73.

Artaud, A. (2001), El teatro y su doble [1978]. Barcelona: Edhasa.

Barba, E. (2002), "The essence of theater", The Drama Review 46. 3: 12-30.

Cavallero, P. (1996), ПАРА ООII: Los motivos literarios de la comedia griega en la comedia latina: El peso de la tradición. Buenos Aires: Facultad de Filosofía y Letras, UBA.

Dubatti, J. (2009), Concepciones de teatro. Poéticas teatrales y bases epistemológicas. Buenos Aires: Colihue.

Dubatti, J. (2008a), Cartografía teatral. Introducción al teatro comparado. Buenos Aires: Atuel.

Dubatti, J. (2008b), "Escritura teatral y escena: El nuevo concepto de texto dramático", Revista Colombiana de las Artes Escénicas 2. 2: 7-18.

Finley, M. I. (1964), Los griegos de la antigüedad. Barcelona: Labor.

Giantsiou Watrinet, C. (2010), Le mime grec antique. Thèse (doctorat de littérature 

comparée). Avignon: Université d’ Avignon et des Pays de Vaucluse.

La Charite, R. C., La Charite, V. A. (1968), "Guillaume Apollinaire: Poet of the Modern Theater", South Atlantic Bulletin 33. 2: 4-7.

Lesky, A. (2001), La tragedia griega [1958]. Barcelona: El Acantilado.

Lusseryan, J. (1961), "La France, laboratoire dramatique, de Jarry à Ionesco", The French Review 35. 2: 127-36.

Macgowan, K., Melnitz, W. (1966), La escena viviente. Historia del teatro universal. Trad. Martínez, H. Buenos Aires: Eudeba.

Melero, A. (1981/1983), “El mimo griego”, Estudios Clásicos 25: 11-37. 